\title{
PROMOTING STUDENTS' AUTONOMOUS LEARNING THROUGH ICT BASED LEARNING IN ICP: A CASE STUDY
}

\author{
Langgeng Budianto
}

\author{
budianto.langgeng@yahoo.co.id \\ Maulana Malik Ibrahim State Islamic University, Malang \\ Alamat Korespondensi: Jl. Gajayana 50 Dinoyo Malang 65144
}

\begin{abstract}
Promoting Information and Communication Technology (ICT) into teaching and learning is a growing area that has attracted many educators' efforts in recent years. Based on the scope of content covered, ICT integration can happen in three different areas: curriculum, topic, and lesson. The evolution of the ICT has changed the way student or individual learns and communicates. It has created a global social network, where everyone is connected, either directly or indirectly, to each other, especially in exchanging, sharing and learning autonomously. This study attemptted to delineate how the students of International Class Program (ICP) at the Faculty of Islamic Education, handle the use of online sources. The students of ICP were selected as the informant. For eliciting information; observation and interview are used in this study. Data are collected by mean of interview guide and field notes. There are 18 students in ICP class. However for the purpose of the study, the researcher selected only three students to participate in the study. The results indicated that three respondents felt positive about using internet to perform task learning experience compared to their experiences in the regular class.
\end{abstract}

Key words: autonomous learning, online resources and International Class Program

\section{INTRODUCTION}

The use of modern technology for teacher training has had tremendous changes over the last few decades. Innovations in technology, the popularity of the internet and its easy accessibility in many parts of the world has made a viable tool for teacher development. The use of the computer, for example, has gone beyond traditional computer assisted language learning and teaching and today the computer is used to take teacher trainees into cyberspace as part of their professional development. In this paper the writer looks at some of the considerations in planning and successfully implementing self-directed learning with technology for the purpose of professional development of English language teachers.

Technology should be used not because it is available or it has been shown effective in some cases. It should be used to enable the process and enhance learning. Inappropriate use of technology can lead to negative effects (Johnson \& Aragon, 2003, p. 31; Russell, 1999). Teacher-designers need to choose proper technology and justify i) why it is needed for the topic; ii) what added values the technology can offer; and iii) how the technology can support the instructional process. Moreover, Roblyer, Edwards, and Havriluk (2004) suggest the following for rationalizing the use of technology: i) high motivation; ii) unique instructional capabilities such as helping students visualize data/problems or tracking learning progress; iii) support for innovative instructional approaches such as collaborative learning and problem-based learning; and iv) increased teacher productivity and student knowledge construction. Thus, technology, especially the internet presents us with new opportunity for authentic tasks and materials, as well as 
access to a wealth of ready-made ELT materials. In addition to this, technology is becoming increasingly mobile. It can be used not only in the classroom, computer room or self-access center, it can also be used at home, on the way to school and in internet cafes (Dudeney, 2007)

At present, the use of technology such as internet sites put on-line by independent, autonomous and self-access language learning center vary considerably in the amount and type of information they provide for their various types of users. The usefulness of technology software, including the computer and internet, for promoting autonomous language learning is questioned by Benson and Voller (1997, p. 46) when they say it is, "an example of a technology which claim to promote autonomy simply by offering the possibility of self-study. As stated by Dudeney (2007, p.8) using a range of ICT tools can give learners exposure to and practice in all of the four main language skills autonomously such as speaking, listening, writing and reading.

In relation to the ideas revealed by Benson, the discovery of strategies used by the "good language learner", or those who are addressed as the successful ones, gives others who are less fortunate to improve their learning strategies. As it is stated by Benson (2001, p. 92) that compared to some other factors like general learning style or personality or personality traits, learning strategies are amenable to change.

Therefore, the need of helping learners who happen to be less fortunate ones, the inverstigation of the learning strategies, employed by the learners who have been successful, become very effective way. Based on the above statements, the idea of conducting a study on the use of the language learning strategy is bound to the idea of promoting autonomy. Studied by Mistar (2001, p.88) had concluded that there was a link between learning strategies and learner autonomy; therefore, one can judge how autonomous EFL learners are from the strategies they employ in learning. In looking at autonomy, the self-access setting can offer learners choices in time, location, and pace of learning; the path through the material to be chosen; and the topics of interest. Technology can play a role in all of these. Advances in information technology are enabling little used educational delivery methods such as internet based learning to gain new life. In addition, the advances in IT have ushered in a new paradigm of on-line learning.

Although the use of IT in language teaching is still not widespread, the use of technology in the classroom is becoming increasingly important, and it will become a normal part of English Language teaching practice in the coming year. According to Dudeney $(2007$, p. 98) there are many reasons for using internet; the internet offers excellent opportunities for collaboration and communication between learners who are geographically dispersed, learners increasingly expect language schools to integrate technology into teaching, using of IT tools can give learners exposure to and practice in all of the four main language skills, speaking, writing, listening and reading.

Based on the background above, the main purpose of this present study is to develop autonomous learning in an online sources. Therefore, the research problems can be formulated into two main problems: (1) how do learners of ICP perceive themselves as autonomous learners? and (2) how does the ICT based learning programs help ICP students to be autonomous learners? (3) what is the value of online resources as a learning aid for the autonomous language learner?

For the purpose of the study, this study tries to explore how the ICP students perceive their autonomy through ICT based program. In addition, the study examines the way the ICT based learning programs help ICP students to be autonomous learners. Given the background, i.e the variety of language competencies and the relevant teaching materials to the needs of the students of the faculty of Islamic Education, Maulana Malik Ibrahim State Islamic University, Malang and the important status of English in the school curriculum, the choice of the study, of course, be primarily made on that basis.

\section{METHOD}

This research is aimed at drawing qualitative conclusion through case study on using ICT based learning program in ICP to build students' autonomous learning. The researcher gathers data through field notes and interviews in the culture under study. The researcher reports the actual data in the form 
of a reported language on the actual data from the natural setting, where the researcher acted as the key instrument. The fact that the researcher has to obtain the data himself and analyze it by himself supported the condition on the importance of a case study approach. Thus a case study in this present study refers to the description and explanation of the nature of autonomous learning using online sources in their learning strategy.

The end of the study is a theory generation that is inductively derived from the phenomenon, namely, the ways the learners carry the learning process specifying on their use of online resources learning strategies. The theory is discovered, developed, and provisionally justified through data collection, analysis, and theory stand in reciprocal relationship with each other. In short, this qualitative case study uses grounded theory approach so the study ends with theory building about how autonomous online learning strategies have become contributing leading the students' success in learning English.

\section{Subjects of the Study}

The subjects of the study are students of the 2009/2010 academic year at Maulana Malik Ibrahim State Islamic University, Maliki, who join the ICP class. Their age ranged between 18 and 19. The proportion of male and female students in the classes are almost equal. One class of ICP is chosen for the present study which consists of 18 students, male and female, with different of language competency, educational background, and public school graduates. However for the purpose of the study, the researcher selected only three students to participate in the study.

\section{Instruments}

The main instrument of the present study is the researcher himself with all his qualifications. He collects data through observations and interviews. He is the only one who is responsible for collecting and analyzing data. In collecting data, he is a participant observer; he only observes the subjects' learning activities. Two kinds of instruments are used for eliciting information: 1) observation and interview.

He uses mini tape recorder, which he thinks is technically easy to operate, practical and reliable interview. Interviewing is carried out using in-depth interview guide with the students about their educational background, the capability of using English and preference in using online resources etc.

\section{Interview}

After obtaining the relevant consent from the participants, the researcher, then, interviews them individually at the end of the semester. The interviews are semi-structured, consisting of pre-written major questions as well as additional questions asked during the interviews. The questions for the interview are grouped into two; major questions and specific questions. Major questions deals with the way to learn English using online and specific questions deals with their preferences of learning.

\section{Data Collection}

Two primary techniques of data collection were used "interview" and "field note". This section illustrates how these techniques are utilized in the study. During this part of the study, the researcher starts to gather raw data. The researcher observed the ICP class. The researcher kept a journal in which fieldnotes were taken at each class meeting.The researcher observed and took fieldnotes for several weeks in the course of the semester. The data were collected through interview to capture the perspective and opinions of participants.

\section{Data Analysis}

The main focus of this study was on the development of autonomy in non English language learners who use online resources as a part of their program. Therefore, one of the important goal of the data analysis process is finding out wheter some of the participants could be characterized as autonomous learners.

All the interviews were transcribed and all the documents are typed manually. By using Dickinson (1993) and Benson (2001) as guides, the researcher looked for evidence in the data that supported the categories of analysis from those two sources. During the process of data analysis, some methods were used to compare and contrast interpretations, develop unforeseen findings and interpretations, and explore findings that are 
anamalous. Data analysis procedures are: (a) data gathering and tabulation, (b) transcribing the data, (c) data interpretation, and (d) drawing conclusion

\section{RESULTS \\ Respondents' Profile as Autonomous Learners}

In an attempt to answer a question about the respondents' profile as autonomous learners, they were given a set of statements in the first interview and asked to comment on them. The statements are listed below with a summary of the respondents' replies.

\section{Being Self-directed Learner}

In line with their response to the way they perceive themselves to be autonomous learners, the respondents said that they manage time well, wrote notes themselves and plan learning well. All the respondents agreed with this statement especially when learning English was significant in their need. Two respondents, however, have visited sites other than the ones suggested by the class. WW and MH claimed that "I use a translation site by going to Google and looking up Indonesia English translation". WW, however, said that her desire to learn the language is not stable. She added, "Sometimes I feel really well-motivated and excited. And sometimes it's a boring. It depends on whether I understand everything. It can be inferred that the respondents are well in managing themselves in integrating internet into their learning.

\section{Working individually and in group}

Two of the three respondents were not sure if they had this quality, but they all agreed that any change in the classroom environment or class would need time to be established. FM explained,

"Suppose I found there isn't any progress in learning language, I would initiate change my ways of learning."

It can be stated that adapting to change depends on the system the learners use it in learning. Two of them are changeable. But, one respondent claimed that his grew up does not help or allow change. Thus, he needs more work to make them change.

In addition, two of the respondents (WW and $\mathrm{MH}$ ) said that they preferred working individually, but one of them preferred working in groups. In a foreign language learning such as English he preferred to work in a small groups consisting of three or four students "FM claimed. FM explained in the first interview, "I enjoy learning in small groups because if I get in a bigger group, I can get a problem to say certain words.

\section{Being curious, flexible and responsible}

When asked about the curiosity and the responsibility of using internet, three respondents possessed these features in various degrees depending on their class assignment. The pattern that emerged from the data showed that the lighter the course load the more curious and motivated the student. FM had this comment, "I lack in curiosity because when I'm learning something my mind does not open up a thousand questions about a certain subject.

Generally,. I'm satisfied with how much I've learned. I don't have a need to learn beyond that." Thus, it implied that the respondents can work more autonomously. It can be inferred that the respondents' learning was more motivating than what they usually did in the traditional class.

Three respondents perceived themselves as generally flexible when learning language. They did not mind if things were changed in class. FM also added that the flexibility depended on other course that might affect the amount of time and effort put into English. Three respondents agreed that they should be more responsible in this class, especially when doing the homework assignments or preparing for a presentation. The researcher believes that responsibility is an outcome of being autonomous learners .

\section{Being able to Learn without an Instructor}

In line with their experience of learning, the three respondents give the statement differently. Thus, when asked about their experience in learning without the teacher, the respondents said that they had had instructor-based learning throughout their history as learners and that they preferred it that way because they needed guidance, planning, motivation, and confirmation that what they were doing was right. Three respondents gave some details about the 
aspect of learning without the instructor. First, FM said in his initial interview;

I actually tried to learn my language on preferred- ways without having an instructor guidance.

Second, MH talked about his experience in learning without an instructor saying in the first interview,

I learned English without an instructor. I learned English more frequently in Ma'had, Intensive English Program and in ICP program.

Finally, WW said in his first interview,

If I had an assignment with a deadline, I usually make it. But if there is no deadline, I usually put it off and I do it myself".

From the data analysis, it can be inferred that autonomous learning are basically personal so that a learner does no have to occupy a certain learning style to choose a certain strategy in order to succeed. It is highly possible that one strategy that is proven to be very effective is found to be ineffective when repeat to others. However, it can also happen that one effective strategy employed by a learner is at the same time effective when employed by others. In other words, learning strategies tend to be highly suhjective in practice.

As has been stated above that learning strategy are personal, so there is not any need for a learner to repeat others' who can successfully employ the learning strategies in order to atain success. If there any possibility to repeat the same strategy, instead of directly adopt, there should be any adjusment and adaptation to make it more practical. A support also comes from O'Malley and Chammot (1990:1) who have earlier stated that learning strategy are special thoughts or behaviors that individuals use to help them comprehend, learn, or retain new information. Thus, in order to retain new information, several learners would employ different strategies to atain success.

\section{Internet Resources Employed by the Three Study Subjects}

The results for this research question showed how the three respondents used online sources in ICP class. During the course of the researcher's observations, the respondents worked mainly individually rather than in groups in the course in connection with their tasks. The students took notes as they listened to course lectures. Through the interview, however, the researcher discovered pertinent information for the study. The finding of the study were based on both the observations and interviews held with the three case study subjects.The following are the results from the interview:

\section{FM's Profile (Fikri Mubarok)}

1. I'm well-motivated having something like the internet or CD recording to listen over and over again.

2. When using online I can be more independent.

3. I enjoy learning English vocabulary from online resource.

4. I can do everything I want with English task via online resources.

5. I'm really responsible for my English task using online.

6. I am quite flexible in learning without an instructor (from website, etc.)

It can be noted from the FM's preferred of learning that his personal ways of learning was independently since he has his own ideas about what and how he should learn. He did not need the teacher's input to tell him how he should access information from the web.

\section{MH's Profile (Muhammad Hilmi)}

1. I demonstrate curiosity about my resources learning from internet.

2. I'm flexible and positive learning language with online resources

3. I can improve my skills such as vocabulary and grammar with online text

4. I am well-motivated to search resource for online.

5. I'm more responsible and interactive with other students with email

6. I sometime chat with English with friends

The researcher reported that that MH's preferred learning language by combination of sef-directed learning and self-taugh. $\mathrm{He}$ approach to language learning by doing all of the activities which the instructor assigns and to do the best he can. He is really well- 
motivated learner either inisde or outside the class.

\section{WW's Profile (Wiwin)}

1. I'm sometime curious working with friend to locate online information .

2. I can be more successful learning when teacher assigns me with web.

3. I am so excited when teacher uses innovative online resources.

4. I'm motivated and interested to spend my time with google translation sites.

5. I'm responsible for searching topics related subject from internet

The researcher found that WW does her homework assignment by locating related subject via WIFI internet. She feels that by doing so she will be successful learning due to many vocabulary learned from the articles. She preferred learning depend on the instructor to make the assignments clear to her and to trust the instructor. All the major categories and their extensions as well as the preferred learning are described in detail in the following section. Her use of internet resources mainly focused on searching for good reading materials for the supporting class rather than for searching information on her own. In her class, she printed out interesting articles based on various topics, such as Islamic scientist, theory of developmental Psychology and Islamic thinkers, namely Al Ghozali, Al Farobi and Ibnu Kholdun.

The researcher found that, although the language learning used by three of the ICP learners varied, it was possible to identify them based on an analysis of qualitative data. For example, WW reported that the language learning that he used in the ICP language learning was memorization and guessing words from the Islamic articles. She reported trying to remember the vocabulary words, for example, in order to be able to use them in the correct context, when she held a conversation with colleagues or instrucutor. She also stated that when learning language from internet online she used a guessing meaning from the text. She tended to examine the words in English and sounded them by guessing the meaning of the word.

$\mathrm{MH}$, on the other hand, also reported that he frequently used guessing to understand meaning from text. He tried to guess what the instructor were saying to him whenever he did not understand a statement or a question addressed to him. He seldom used dictionary to understand meaning, but working with interpreting of meaning from the context. Different from FM and MH, WW reported that she tried to write down most words that she hear during the lecture and when she came across unfamiliar words, she then write those words in her note book.

Three of the respondents claimed that they were independent to learn but they also welcomed cooperation with classmates in a language class where communication was key to learning. The more autonomous students would know what they needed to do. On the contrary, the learners who are less autonomous wanted somebody to control things and tell them what to do.

In general, the respondents perceived themselves as flexible; they did not mind if they learn with online materials. The flexibility depended, to a degree, on other coursework that might affect the amount of time and effort put into English. They all agreed that any change in the classroom environment or class structure would need time to be established. The features of curiosity and motivation were possessed by three of the respondents.

In line with the responsibility in the class, the respondents expressed that they should be more responsible in the class, especially when doing the homework assignments or preparing for a presentation. They claimed that online materials were really helpful to support their language acquisition. They are aware of themselves of using references from online source as their aid for class presentation. All the respondents believed they had more confidence when they sat quietly in the classroom presentation. When they were asked to speak, their confidence level was higher because they were sure if what they were saying was correct. It can be noted that the students' confidence level depended on their knowledge of the language and the skills they used.

In addition, the students' interest was improved automatically since the respondents has been accustomed to using online sources as their extra materials, especially when the topic of presentation or project was of interest 
to the learners. This was exemplified by better searching for answers to questions faced by the participants as well as looking up words in the dictionary more quickly and accurately. The researcher found that the class website was interesting and challenging. WW says that:

"I found website on Islamic thought more interesting than looking through the book and trying to understand the book. Website has things I could possible need.

The researcher also noted that most of the students developed such skills especially by searching on the Internet. The respondents used various ways of how to use email, blogs and web quest in website for studying language. They need links that are especially useful to them when they are studying on their own. They stated that having many links, especially topics related to class, make the learning experience interesting and exciting.

When asked about the link is created to become autonomously, the respondents viewed in different statements. FM viewed that he visited as many as links as possible, and use the material available to him. He stated that the class website has just about everything he could possibly need at the early stage of learning English. Two others respondents, WW and $\mathrm{MH}$ have the same perception that having many links in language learning make the learning experience exciting. Watching the videos repeatedly and searching articles in the internet are the two regular activities that they carried out. Three of the respondents like to search a source of information and links related to learning the English language. It comprised of various link sections such as section on Wikipedia, BBC Leaning English, EBSCO-Com (an international journal) online bilingual dictionary, and subjects related topics to class.

In addition, when asked about the frequency of the respondents to visit the web, two of the respondents stated that they visit the class website minimally once every day. They usually visit it to do the searching articles related to class. However, one respondent noted that she uses the class website just a few times in a week. She added that she can use the website just to keep listening or watching film from You tube. It can be inferred that the more the respondents use the online resources the better their language skills will be. Thus, they believe to be more autonomous and independent than one who does not show as much interest on online

The respondents thought of the traditional method (non ICT Based Learning) and textbook as boring and uninteresting English instruction, while the online, on the other hand were more fun and interesting. One respondent $(\mathrm{MH})$ expressed the idea that "It (online bilingual dictionary) got my attention and stimulated curiosity" The two other respondents (WW and FM) liked the online resources just because of the technological function. Through the graphics and sound, a respondent said she "enjoyed learning from the internet more than reading from colorless textbook " (WW). One respondent also said, "I like this type of learning that included different kind of media like the internet, instead of using only textbook" (MH).

However, it seems too soon to make a conclusion at this stage that the online sources can actually increase learner's motivation simply because they are new and difficult from the traditional method. The three respondents mentioned the benefit of the online resources in helping them to become more active in their language learning:

This (online resources) is an innovative ways of learning. I like to visit EBCO.COM $(W W)$.

I like the online class because we had more freedom in our thinking as we learned new things and worked as a team (MH)

FM stressed the significance of the use of the internet in the class in the following statement;

When I liked most about online resource was a chance to use internet technology which becomes very important to gain knowledge.

When asked about the use of online resource to learn language, the respondents tried using English for email or chat, but they said they would like to learn how to do that. The respondents indicated that in their second interview where WW said, "I started using it more because pronunciation has become a greater problem for me. So to work on my pronunciation, it really helps to listen to the online voice that we have to improve my 
pronunciation." The respondents noted that they could make more use of the online resources especially in the area of improving pronunciation.

Three of the respondents stated their appreciation that online resources were available to them as a source of support and motivation. They highlighted the importance of having texts as well as interactive video materials to use at a convenient time and place. In addition, online resources gave them independence from their instructor, who was not accessible at all times, and enabled them to go beyond the scope of the class.

The respondents also expressed that the value of online resource was useful for motivating and fun learning method for ICP class because of its multimedia capacities and task-based activities. They admitted that the reading in traditional class may be boring for the learners, as the pictures contained in the textbooks were unappealing and some materials were outdated, they believed that the online resources and its authenticity may provide a better source of information.

In addition to this, the three respondents claimed that online resources are suitable to them as a source of support and motivation in their language class. They especially emphasized the importance of having texts as well as interactive film on their class website for them to use at a convenient time and place to learn. In addition, they said that online resources gave them independence from their instructor. WW wrote in her journal, "Using online resources helps me take control over my language learning process".

Besides, the three respondents stated that the online resources in their language learning are beneficial for interactively practice their language skills, especially speaking and listening. They also said online resources provided information the students would not be able to obtain by any other means. MH said in the first interview, "Online resources give me so much variety to choose from. When studying from a book all the time, it's boring. But when you go online, you listen to the recording, you watch the film or video and you feel the interaction."

Meanwhile, FM revealed that the use of online resources are very important part of learning language. He says that "I need accessible materials on the website; I do not have to be in class or in the library. I could just do everything at home, emailing or chatting to friends and teachers.

Two respondents, FM and WW agreed that the class has taken them in improving their English skills, emphasizing grammar, vocabulary, and speaking in the end of the course. The respondents felt confident "enough to survive in an ICP class,". In contrast, one respondent felt that the progress slowed down toward the end of the semester.

All the respondents agreed with this statement especially when learning English was significant in their need. Two respondents, however, have visited sites other than the ones suggested by the class. WW and FM claimed that "I use a translation site by going to Google and looking up Indonesia English translation". WW, however, said that her desire to learn the language is not stable. She added, "Sometimes I feel really wellmotivated and excited. And sometimes it's a boring. It depends on whether I understand everything.

The problem indicated by the three respondents in their reflections included the difficulty of vocabulary. Even though they claimed that the topic and content of the selected articles was interesting and easy to understand, two of the respondents admitted that they had trouble with the vocabulary exist in the article. One respondent consistently expressed not liking to read on the computer screen because she could not mark or highlight the page, while two other respondents said they preferred to read on the computer monitor because they found it easier than reading a book.

In summary of the respondents' use of online resources showed that they had to be actively involved in the class assignment and perform the task by themselves with little help from the teacher. They struggled themselves to understand the lengthy text and difficult vocabulary. As the lesson progressed, the respondents little by little became more involved in finding ways to support their online learning, such as finding relevant materials and selecting appropriate links. Moreover, the respondents expressed their interest in creating resource materials by themselves for other class. It implied that they were proficient in using the internet access. 


\section{CONCLUSION}

The researcher explored the students' self-choice of studying language in an ICP class. It was found that those who said that they would choose to study English with internet sources used significantly more strategies for learning English than those who said they would not. This finding on selfinitiative for learning was similar to that found in a study investigating how prior English learning affects their language learning. In other words, when learning is selfinitiated, there is more application of strategies which might lead to a more successful learning outcome. The benefits of learning with resources from internet are as follows: (a) learners can work at their own pace, according to individual needs, interests and learning preference - it can be very motivating; (b) access to appropriate supporting resources is especially important for learners with disabilities or specific learning needs. (c) learners learn to learn autonomously, learning focus on the process as well as the product, learners develop appropriate learning activities, (d) providing life-like or authentic communication activities, through group work, simulations and use of authentic materials and (e) access to new technologies increase general computer literacy skills, and gives practice in use of specialist language tools such as translation packages, electronic dictionaries etc.;

Experience of internet resource learning will also prepare the language learner to carry on learning when a course of study has ceased or when support structures are no longer in place. The traditional period of residence abroad, for example, provides a difficult challenge for any learner if they are going to make the best of the learning environment both in terms of their language competence and their general coping strategies.

The experience of independent learning and the development of key transferable skills will all lead to greater employability.

Overall, all three respondents felt positive about using internet to performance task learning experience compared to their experiences in the regular class. FM and expressed their frustation with the monotonous class activities, so both of them welcomed new learning activities using online materials, whereas WW did no think that there was much differences between performance task in the traditional class and using internet sources task. All of them mentioned that they liked the performance task. Three respondents (FM, MH and WW) reported that the usefulness of the internet resources, as it increased their motivation due to the use of innovative and more interesting activities.

\section{REFERENCES}

Benson, P. (2001). Teaching and Researching Autonomy in Language Learning. Applied Linguistic in Action Series. London: Logman

Benson, Phil \& Voller, Peter, eds. (1997). Autonomy and Independence in Languag Learning London: Longman

Chamot, A.U. \& El-Dinary, P.B. (1999). Children's Learning Strategies in Language Immersion Classrooms. Modern Language Journal 83, 319-338.

Dickinson, L. (1993). Self-instruction in Language Learning. Cambridge: Cambridge University Press.

Dudeney, G and Hockly, N, .(2007). How to Teach English with Technology. Pearson Education Limited

Johnson, S. D., \& Aragon, S. R. (2003). An instructional strategy framework for online learning environments. New Directions for Adult and Continuing Education, 100, 31-43. 
Mistar, J. (2001) Maximizing Learning Strategies to Promote Learner Autonomy. TEFLIN Journal, 12 (1), 88-100

O’Malley, J. M. \& Chamot, A. U. (1990). Learning Strategies in Second Language

Acquisition. Cambridge: Cambridge University Press

Oxford, R. (1990a). Language Learning Strategies: What every Teacher Should Know. New York: Newbury House.

Oxford, R.L. (1990). Language Learning Strategies: What Every Teacher Should Know. Rowley, MA: Newbury House.

Roblyer, M. D., Edwards, J., \& Havriluk, M. A. (2004). Integrating Educational Technology into teaching (4th Ed.), Upper Saddle River, NJ: Prentice Hall.

Russell, T. L. (1999). The no Significant Difference phenomenon, Raleigh: North Carolina State University. 